\title{
Educación religiosa escolar, una mediación crítica para comprender la realidad
}

Education religieuse scolaire, une médiation critique pour comprendre la réalité Educação religiosa escolar, uma mediação crítica para compreender a realidade

\section{Resumen}

Formular la pregunta por la pertinencia de la educación religiosa es indagar por su objeto de estudio, objetivo de formación, método y función en la escuela y la sociedad. Este artículo, contextualizado en la modernidad y su pretensión de libertad, pretende valorar el alcance crítico de este saber, plantear la necesidad de una opción por su fundamentación desde la teología de la liberación y pedagogía liberadora, como proceso de concienciación, y aportar a la educación dentro de la racionalidad secularizada. La reflexión recoge las intuiciones en torno a la importancia de la Educación Religiosa Escolar, ERE, en la escuela, como parte de la investigación sobre la ERE liberadora, financiada por la Pontificia Universidad Javeriana.

\section{Palabras clave descriptor}

Educación religiosa, libertad religiosa, religión, fetichismo, conciencia, educación formal.

\section{Transferencia a la práctica}

El artículo presenta los elementos argumentativos para la valoración de la Educación Religiosa Escolar en clave liberadora, para permitirle al docente establecer un diálogo interdisciplinario con las ciencias sociales y hacer de la formación para el ejercicio de la libertad religiosa un fundamento crítico para comprender la realidad y su racionalidad.
Juan Alberto Casas-Ramírez

PONTIFIIIA UnIVERSIDAD JAVERIANA Bogotá, Colombia

jcasas.smsj@javeriana.edu.co

Daniel de Jesús Garavito-Villarreal

PONTIFICIA UnIVERSIDAD JAVERIANA Bogoté, Colombia garavitod@javeriana.edu.co

José Luis Meza-Rueda Pontificia Universidad Javeriana Bogotá, Colombia joseluismeza@javeriana.edu.co

José Orlando Reyes-Fonseca PontiFicia Universidad JaVERIANA Bogotá, Colombia jose.reyes@javeriana.edu.co

Gabriel Alfonso Suárez-Medina Pontificia Universidad JaVeriana BogotÁ, Colombia gs000123@javeriana.edu.co

Para citar este artículo / To cite this article / Pour citer cet article / Para citar este artigo Lara-Corredor, D. E.; Casas-Ramírez, J. A.; Garavito-Villarreal, D. de J.; Meza-Rueda, J. L.; Reyes-Fonseca, J. O. \& Suárez-Medina, G. A. (2015). Educación religiosa escolar, una mediación crítica para comprender la realidad. magis, Revista Internacional de Investigación en Educación, 7(15), 15-32. 
Key words plus

Religious Education, Religious Freedom, Religious, Fetishism, Consciousness,

Formal Education.

\section{Mots clés descripteur}

Education religieuse, liberté religieuse, religion, fétichisme, conscience, éducation formelle.

\section{Abstract}

To address the question of the relevance of religious education is to inquire for its object of study, formation objective, method and function at the school level and society. This article, contextualized in modernity and its claim to freedom, aims to value the critical scope of this knowledge, ad dress the need of an option for its substantiation based on the liberation theology and pedagogy for liberation as a process of consciousness, as well as to contribute to education within the secular rationality. The reflection brings together institutions around the importance of Religious Education at schools, ERE, as part of the research on the liberating ERE, funded by the Pontificia Universidad Javeriana.

\section{Transfer into practice}

The article presents the argumentative elements for the assessment of Religious Education at schools in liberating key, in order to allow the teacher to establish an interdisciplinary dialogue with the social sciences and make education - for the exercise of religious freedom - a critical foundation for understanding reality and rationality.

\section{Résumé}

Formuler la question de la pertinence de l'éducation religieuse, c'est indaguer sur son objet d'étude, l'objective de formation, la méthode et la fonction dans l'école et la société. Cet article est contextualisé dans la modernité et son prétention de liberté, il a l'enjeu de souligner le degré critique de ce savoir, d'exposer le besoin d'un choix pour fonder ce savoir depuis la théologie de la libération et la pédagogie libératrice, en tant que processus de conscience, et contribuer à l'éducation à l'intérieur de la rationalité sécularisée. La réflexion recueille les institutions autour de l'importance de l'éducation religieuse scolaire, ERS, à l'école, en tant qu'une partie de la recherche sur l'ERS libératrice, financée par la Pontificia Universidad Javeriana.

\section{Transfert à la pratique}

L'article présent les éléments argumentatifs pour la mise en valeur de l'éducation Religieuse Scolaire en clef libératrice, pour permettre à l'enseignant établir un dialogue interdisciplinaire avec les sciences sociales et faire de la formation pour l'exercice de la liberté religieuse un fondement critique pour comprendre la réalité et sa rationalité.

\section{Palavras-chave descritor}

Educação religiosa, liberdade religiosa, religião fetichismo, consciência, educação formal.

\section{Resumo}

Formular a pergunta pela pertinência da educação religiosa é investigar pelo seu objeto de estudo, objetivo de formação, método e função na escola e a sociedade. Este artigo, contextualizado na modernidade e sua pretensão de liberdade, visa valorizar o escopo crítico deste saber, levantar a necessidade de uma opção por sua fundamentação desde a teologia da libertação e pedagogia libertadora, como processo de conscientização, e contribuir para o ensino dentro da racionalidade secularizada. A reflexão colige as intuições em torno da importância da Educação Religiosa Escolar ERE, na escola, como parte da pesquisa a ERE libertadora, financiada pela Pontifícia Universidade Javeriana.
Transferência para a prática $\mathrm{O}$ artigo apresenta elementos argumentativos para a valorização da Educação Religiosa Escolar em chave libertadora, para permitir o docente estabelecer diálogo interdisciplinar com as ciências sociais e fazer da formação para o exercício da liberdade religiosa um fundamento crítico para compreender a realidade e sua racionalidade. 


\section{Introducción}

Con la creación del Estado moderno, la escuela se convirtió en una institución importante para la formación de las nuevas generaciones en las sociedades modernas (Aguirre, 1991, pp. 75-84), pues el bien social llamado formación pasó a manos del Estado como un bien público, la educación, haciendo de la escuela un escenario donde se establecen las relaciones de enseñanza-aprendizaje entre docentes y estudiantes mediante los saberes. Así, una de las tareas del Estado es la formulación de políticas educativas por medio de leyes de educación.

El artículo 67 de la Constitución Política de 1991 indica que la educación es un derecho de la persona y un servicio público (Colombia, 1991, art. 67), y la Ley General de Educación o Ley 115 de 1994, en su artículo 5 señala los fines de la educación para lograr la formación integral de los niños y jóvenes (Colombia, 1994). Uno de esos fines es la formación de la dimensión espiritual y el reconocimiento de los principios democráticos del pluralismo y la tolerancia. Para hacer realidad estos fines, la Ley 115/94 establece los objetivos y las áreas de formación obligatoria, en particular, el área de educación religiosa con el fin de formar en las dimensiones de sentido, religiosa, trascendente y espiritual, propias del ser humano.

Con el reconocimiento del área de educación religiosa, como obligatoria y fundamental, el Estado concreta, de alguna manera, lo prescrito en la Carta Constitucional en el artículo 19 sobre el derecho a la libertad de cultos, en consonancia con los principios propios de la identidad del Estado democrático, como el pluralismo, la tolerancia, la moral y el respeto por la identidad cultural, referidos al derecho a profesar libremente la religión.

Pero ¿cuál ha de ser el alcance de la formación en el área de educación religiosa? En primer lugar, esta área debe formar para el reconocimiento y ejercicio de la libertad de cultos, es decir, la formación en la libertad de la dimensión religiosa del sujeto; en segundo lugar, el área está llamada a valorar las tradiciones religiosas que le han dado identidad a la cultura de los pueblos y reconocer la mediación crítica que tiene el estudio de lo religioso y de la religión para comprender la realidad en la tensión y dinámica, propia de las relaciones humanas, de fetichizar las instituciones e "idolatrizar" las realidades humanas. En tercer lugar, se busca darle énfasis epistemológico y metódico a este saber con las mediaciones propias de la educación religiosa, la teología, como disciplina fundante, y la pedagogía, como reflexión de la educación, que en este caso será reflexión sobre la educación religiosa escolar. Por ello, el artículo girará en torno a estos tres aspectos.

\section{Una educación religiosa como formación para el ejercicio de la libertad}

Si la escuela surge en el contexto de la modernidad, debemos contextualizar la educación religiosa escolar en la misma época, pues fue a partir de la modernidad, que se caracterizó por la exaltación del sujeto (González, 1997, p. 7) desde el primado de la libertad, que la escuela busca educar en la libertad. Pero valorar en sí misma la libertad es apreciarla más allá de su concepto abstracto, absoluto y metafísico; la libertad se va concretando en formas de acción humana que dinamizan la cotidianidad de la vida, como la libertad de pensamiento, movilidad, conciencia, desarrollo de la personalidad y libertad religiosa, entre otras. Por ello, para el logro del objetivo de darle sentido a la libertad, la sociedad y el Estado moderno entendieron que las religiones, en particular desde su lenguaje, tienen una reserva de
Descripción del artículo | Article description | Description de l'article | Artigo descrição

Este artículo recoge las intuiciones del grupo de investigación en torno a la importancia de la Educación Religiosa Escolar, ERE, para la formación de la dimensión religiosa del sujeto y la lectura crítica de la realidad. Se deriva de la investigación sobre la ERE liberadora, que pretende identificar los elementos liberadores en la ERE presentes en algunas instituciones educativas. Proyecto financiado por la Pontificia Universidad Javeriana y dirigido por José Luis Meza y Gabriel Suárez, de la Facultad de Teología, como investigadores principales, junto con los coinvestigadores Juan Alberto Casas, Daniel de Jesús Garavito, José Orlando Reyes y David Eduardo Lara. 
sentido que le permite a la sociedad articular las acciones de los asociados en torno a un saber y experiencia cultural: " [...] algo se dice en él —discurso religioso- que no se dice en otras modalidades del discurso: discurso ordinario, discurso científico, discurso poético" (Ricoeur, 2008, p. 51).

Así, el área de educación religiosa, por su aporte de sentido, busca la formación en la comprensión, alcance y ejercicio de la libertad desde lo religioso como forma de concretar las dimensiones transcendente, espiritual, religiosa y de sentido del sujeto. Además, la sociedad moderna reconoce que la religión hace parte de la matriz cultural que brinda identidad a los pueblos y posibilita que el sujeto se desenvuelva a partir del ejercicio de esa libertad religiosa.

En ese orden de ideas, se comprende la necesidad de la formación religiosa en la escuela, de cara no solo a la tradición cultural de los pueblos en su contexto espacio-temporal, lo que exige un estudio del fenómeno religioso cultural, sino, además, al desarrollo de la libertad, desde lo religioso, en el sujeto, es decir, desde su capacidad de fe genérica para madurar a una capacidad de revelación que lo religa con un proyecto de vida, exigiéndole una formación desde la experiencia religiosa que se expresa por medio de su lenguaje (Ricoeur, 2008, p. 52).

La escuela, por tanto, forma en la libertad religiosa acorde con los principios de pluralismo, es decir, la aceptación de las distintas expresiones culturales religiosas y no religiosas; tolerancia, como el derecho al reconocimiento en pie de igualdad jurídica de los grupos, sean estos mayoritarios o minoritarios, como expresión de la cultura religiosa; diversidad, para ampliar la comprensión de la dimensión trascendente dentro de distintas manifestaciones que se dejan aprehender en sus expresiones lingüísticas (Ricoeur, 2008, p. 55).

Sin embargo, en el ámbito propio de la libertad, la educación religiosa escolar en perspectiva liberadora ha de aportar una lectura crítica de la realidad que va construyendo el sujeto, porque, ante la condición limitada que experimenta frente a sí mismo y frente a lo externo, sea la naturaleza, el universo y el misterio, el sujeto tiende a buscar seguridades, consideradas como divinidades, que le brinden tranquilidad y garantías alcanzables (Cavadi, 1998, p. 63); además, porque "cualquier realidad puede ser revestida por el hombre con el brillo de lo divino y adorar después como su dios" (König, 1989, p. 54).

La persona libremente tiene la posibilidad de hacer de la realidad un ídolo para adorar, para ser exaltado en el culto, en contravía con la Trascendencia, lo Otro o la divinidad, generando rivalidad y distorsionando la imagen de la divinidad por su manipulación (Sicre, Castillo \& Estrada, 1989, p. 54). Así, "los ídolos de hoy son los líderes, las instituciones —especialmente el Estado-, la nación, la producción, la ley y el orden y toda obra fabricada por el hombre" (Sicre, Castillo \& Estrada, 1989, p. 135); incluso, las mismas cosas o acciones buenas del sujeto se pueden convertir en ídolo: sus deseos, sus intereses, sus valores absolutizados y proyectos como la paz, el bienestar, el proyecto de historia, con la confianza y convicción fiel de que todo depende del sujeto mismo, enajenando y sacrificando la propia libertad.

Entonces, lo religioso, como concreción de la libertad del sujeto, implica una actitud crítica y/o profética que desenmascare los propios ídolos y ofrezca el coraje para denunciar sus opresiones.

En la misma función de denuncia y conversión proféticas, la Iglesia recuerda que toda absolutización de una cosa creada es una ofensa al único Absoluto y Creador porque erige y sirve a un ídolo que pretende suplantar al mismo Dios. 
Además de ofender a Dios, toda absolutización destruye y desorienta al hombre. La vocación del hombre solo se realiza cuando se promueve hasta su dignidad de hijo de Dios y partícipe de su vida divina. Esta trascendencia del hombre no es evasión de los problemas de la tierra, ni mucho menos opio que lo distraiga de sus obligaciones en la historia; al contrario, en virtud de su destino trascendente, el hombre posee una capacidad de crítica permanente frente a los quehaceres de la historia y le da una poderosa inspiración para alcanzar metas cada vez más altas (Romero, 1979, p. 145).

El área de educación religiosa, en la escuela, debe aportar a la formación de la conciencia crítica de los estudiantes, para que puedan discernir lo que de la realidad el ser humano ha absolutizado, es decir, lo que ha convertido en ídolo o fetiche, sin ser necesariamente una realidad religiosa. Su reflexión no puede reducirse a simple pensamiento de lo religioso o de las cosas del misterio, como una ideología más, como un "saber de relleno" en la escuela, desconociendo la función crítica ante el sistema-mundo que orienta a la humanidad hoy; la educación religiosa, fundamentada en una teología liberadora, no puede ser un discurso acomodaticio de la secularización o una exhortación sin más que oriente la preocupación individual de la salvación, sino una reflexión crítica que suscite en los estudiantes la preocupación por lograr la síntesis entre la fe y lo político, la fe y la justicia social.

\section{Una educación religiosa como crítica a la racionalidad del momento}

La educación religiosa escolar hoy, como uno de los saberes que van articulando la argumentación formativa en la escuela, es necesariamente una tarea contextualizada de lo religioso en las circunstancias contemporáneas y "sus procesos de ilustración, secularización y emancipación" (Metz, 2002, p. 85), con la particularidad de que en la secularización queda "básicamente oculta la clara fuerza liberadora y crítica del cristianismo en relación con la historia y la sociedad" (Metz, 2002, p. 86).

Pero en ese mismo contexto lo religioso cobra su razón crítica-práctica al asumir la praxis que le da sentido al sujeto en la historia, con un dinamismo liberador, utópico y esperanzador, frente a los nuevos totalitarismos de los cálculos utilitaristas (Metz, 2002, pp. 90-91). Por ello, la religión recupera su carácter de memoria, que narra una libertad liberadora, frente a las absolutizaciones del progreso.

Y aquí se halla también, finalmente, la base para una crítica teológica de las teorías de la ilustración y una emancipación, abstractas y totales, que en relación con la historia del sufrimiento humano, aparecen como una forma de historia demediada de la libertad. Por eso es posible retomar los temas 'revelación e ilustración', 'salvación y emancipación' y 'fe y crítica' sin necesidad de tener que ignorar o reprimir los problemas planteados por la época de la crítica (Metz, 2002, p. 95).

No se debe olvidar que dentro de la lógica de la construcción de la historia, lo religioso, como parte de la cultura, también le ha dado identidad a la historia, marcando o dejando huella de la forma como la comunidad humana, local o globalmente, va construyendo horizontes de comprensión y mundo con la realidad. De igual manera que estos proyectos de historia y de mundo se plasman en su racionalidad, es decir, en la forma misma como se conoce y se interpreta la realidad. 
Por lo anterior, se debe considerar que la reflexión en el área de educación religiosa no está ajena a las racionalidades que se van formando en la historia de las ideas y que caracterizan una época, por ejemplo la modernidad:

Una fe concebida como rigurosamente amundana suscita la sospecha de poder convertirse, por su asilamiento privatista, en la exaltación ideológica o en la paráfrasis simbólica de todo proceso histórico-social del mundo. [...] Para esta 'teología del mundo' es y vale como cristiano lo que a raíz de la llustración y de su 'época crítica' se considera y vale como racional. [...] Todo se asemeja en exceso a una sospechosa canonización religiosa del desarrollo real y de las tendencias reales de la moderna historia de libertad e ilustración, y a una infravaloración de la dialéctica intrínseca de los procesos de secularización, emancipación e iluminación (Metz, 2002, p. 86).

Ahora, una de las formas de construcción de los proyectos de sistema-mundo ha sido la globalización, entendida esta como estrategia de homogeneización del mundo de la vida, que hace que se uniformen las expresiones humanas del pensar, actuar y hablar, tanto en la política como en la economía, las ciencias, la educación, el idioma y lo ético: "Por lo menos, se dirá, hay hoy en día un peligro de uniformización cultural" (Calvez, 2005/2003, p. 50).

\section{La racionalidad actual: ¿globalización o mundialización?}

La globalización se ha revestido de un halo sacral o de misterio, ya que la sociedad entroniza la misma comprensión del mundo en el marco de la divinidad, fetichizando las relaciones y haciendo del proyecto de globalización una idolatría. Entonces, en la historia, los proyectos globalizadores generan ídolos, con sus trampas religiosas, pues disfrazan la realidad con ropajes de dioses o semidioses, acompañados de sus ritos y prácticas cultuales, incluso, con justificaciones teológicas que hacen ver al ídolo como una representación de la divinidad y su racionalidad como su lenguaje (Cavadi, 1998, p. 67).

Dentro de esa lógica, la humanidad se encuentra en un cambio de época, caracterizada por los cambios presentados en la política y en la economía (Castillo, 1997, pp. 9-10). El ámbito de la política se ha demarcado por la proclamación editorial del fin de la historia, que anuncia la hegemonía del sistema del liberalismo y el decaimiento de las visiones socialistas. Además, alude a "[...] una política de (apertura de fronteras —hasta forzar la apertura de las fronteras_...)" (Calvez, 2005/2003, p. 42). En el ámbito de la economía, el cambio se ha dado en el neoliberalismo económico, que ha llevado a la globalización de la economía de mercado y el progresivo distanciamiento entre pobres y ricos, que está agudizando la violencia y la deshumanización (Castillo, 1997, p. 10).

¿Cómo entender esta globalización? El jesuita francés Jean-Yves Calvez S.J. (2005/2003, p. 42) señala que la palabra globalización hace referencia a una política consistente en una apertura de las fronteras. Esta globalización emerge por el imperialismo de los estados capitalistas, al implementar estrategias que se dan en la economía del libre mercado y los tratados de libre comercio auspiciados por las empresas multinacionales y los organismos multilaterales como el Fondo Monetario Internacional y el Banco Mundial; en la intervención total, en cada Estado, de organismos políticos internacionales como la Organización de Naciones Unidas, o regionales como la Organización de Estados Americanos, y los organismos económicos, que intervienen políticamente en las decisiones de los 
Estados tanto en la elaboración como en la ejecución de los proyectos.

En lo cultural, la globalización se ha dado con la homogeneización del idioma, para que todos en el mundo hablen el mismo de las potencias del mercado; en la educación, se brindan proyectos educativos de acuerdo con las necesidades del desarrollo y la economía, como estrategia de las potencias para dominar el acceso a la ciencia, ya que, según Riay Tatary-Bakry (2000, p. 13), secretario general de la Comisión Islámica de España, la potencia económica y política de una nación radica en su capacidad de gestionar las nuevas tecnologías y exportar su conocimiento.

Pero esta realidad de la globalización, entendida como internacionalización del "sistema-mundo" del mercado, no ha tenido la misma homogeneización en el ámbito de la religión, pues en el contexto de un mundo secularizado, las expresiones son ambiguas: por un lado, se ha implementado el mercado de lo religioso, y por otro, la "fetichización" o idolatrización del sistema como una nueva religión. Ya los obispos de América Latina, reunidos en Santo Domingo, en su documento de trabajo señalaron: "Absolutizar una cultura como si fuese la única apta para vivir la fe, sería idolatría" (CELAM, 1993, 523, Instrumentum laboris).

La actual globalización ha fetichizado las relaciones humanas dentro de la lógica del consumo, para lo cual, la misma economía se ha convertido en una religión: con su dios, el dinero; con sus centros cultuales, los bancos; y con los ritos de exaltación como los actos de las bolsas de valores de los principales países que jalonan la economía mundial. De esta forma, se introduce la absolutización del sistema-mundo de la economía, como un sistema sacralizado en torno a un nuevo ídolo o fetiche: el dinero. Ante tal realidad, la educación religiosa escolar ha de revitalizar su dimensión profética si ella quiere ser liberadora, es decir, pronunciar su voz de denuncia y crítica de esta realidad que está enajenando al sujeto, y proclamar la justicia como expresión de la fe.

Contrario a la globalización está la mundialización, que permite tener una comprensión del mundo, más allá de los límites geográficos e ideológicos, por cuanto el entendimiento que se tiene, gracias al desarrollo de las tecnologías de la información y la comunicación, no se hace desde un referente ideológico sobre el entorno performado por la homogeneización etnocéntrica del mundo, sino desde la comprensión de un mundo cada vez más interrelacionado, codeterminado, interconectado.

¿Qué se puede entender por mundialización? Esta palabra, que corresponde en otros idiomas al adjetivo inglés worldly, en alemán weltlich y en francés mondialisation (Calvez, 2005/2003, p. 41), entiende el hecho de que los problemas y necesidades humanas hoy tienen una dimensión mundial; ya los problemas no se limitan al ámbito local, nacional, ahora son tratados en todo el mundo (Calvez, 2005/2003, p. 42). Por tanto, la mundialización obedece a una dinámica de comprender y asimilar la realidad desde el ámbito mundial, es decir, todo el mundo se encuentra interrelacionado y codeterminado.

La mundialización refiere directamente al mundo mismo, a todo el sistema planetario, que ya está al alcance de los sentidos de manera directa o virtual, de las distancias a la inmediatez (Carrera-i-Carrera, 2005, p. 13) por los adelantos de la tecnología de la información. Así, ante la crisis de los grandes metarrelatos que pretende la homogeinización de la cultura dominante, se dan paso las expresiones culturales de los diferentes pueblos que le aportan a la humanidad sus conocimientos ancestrales, su sabiduría de la vida, la compresión de la trascendencia, como la relación que permite crear otro mundo posible, del gran relato al pequeño relato (Carrera-i-Carrera, 2005, p. 19). En ese contexto de la mundialización, la religión aportará la riqueza de su comprensión de la vida, sus valores y el reconocimiento de lo Absoluto, como fundamento de la humanidad.

\section{La secularización como fundamento del mundo globalizado}

Es en la modernidad cuando surge el proyecto del sistema-mundo secularizador, contrario al mundo sacral que crea el dualismo profano-sagrado. La secularización, en su forma de comprensión vulgar, es la ruptura de la unidad religiosa y moral con el Estado, que caracterizó la Europa medieval y su proyecto del orbe cristiano, para dar paso a una nueva manera de pensar las cosas del pueblo con independencia de las cosas de la Iglesia, las cosas del Estado de manera autónoma, a partir de una ética normativa basada en la razón y válida para todos los seres racionales (Ferrer, 2000, p. 129).

La imposición del mundo laico exigió la ruptura con el mundo clerical al dejar al margen a Dios y la influencia de la Iglesia en las decisiones del Estado. Así, la filosofía sustentó la secularización, al declararle la muerte a Dios, para inaugurar el proyecto de la modernidad cimentado en la filosofía de la sospecha; la nueva forma de pensar no dependía de una moral heterónoma sino de una ética autónoma fundamentada en el primado de la razón (Ferrer, 2000, p. 199). Este secularismo establece la racionalidad como único criterio de validez e, incluso, supone la separación de la persona humana con respecto a Dios y llega incluso a su negación.

En este contexto no hay hostilidad hacia la religión, sino que se prescinde de ella, dejándola en el ámbito de lo privado, sin influjo en el mundo de la vida en los ámbitos políticos, económicos, sociales y 
culturales, dejando en vigencia la sospecha de la religión y depositando la confianza en el progreso de la ciencia y en el valor de la autonomía. Se generaliza así una actitud, jalonada por la ética o filosofía moral y fundamentada en la especie de neutralidad de la razón y de la ciencia, que inaugura un universalismo racionalista, libre de las raíces culturales y que mira con sospecha las particularidades de las culturas y de las tradiciones humanas o religiosas (Gafo, 2003, p. 78). Sin embargo:

Es evidente que la modernidad ha fracasado como proyecto presente y futuro en las cuatro quintas partes de la geografía mundial. El Sur dependiente y explotado solo ha vivido su fracaso en la sociedad moderna, ha desmentido radicalmente la idea de progreso de la civilización occidental, y ha descubierto en carne propia que el discurso modernizador encierra hegemonismos, represión, perpetuación de la injusticia, totalitarismo (Fernández, 1991, pp. 51-55).

Por ello, la educación religiosa ha de ser un saber crítico en la escuela, que le permita al sujeto desenmascarar los nuevos ídolos que justifican el sistema-mundo secularizador y su racionalidad. Si la globalización de la economía, como realidad presente, pretendió ser el discurso racional homogeneizador que permitiera el progreso de todos los pueblos, quedó corto ante la realidad de países cada vez más empobrecidos y enajenados, ya que su modelo no les permite lograr, aunque sea, su dignidad.

\section{La desfetichización como actitud critica a las nuevas idolatrías}

La realidad del mundo de la vida, que quería escaparse del control de lo religioso, por medio de las instituciones religiosas, para pasar a una libertad dada por una mentalidad secular, terminó generando una nueva realidad distorsionada de lo religioso: la idolatría.

Así, el Estado, la escuela, la fábrica, el batallón, el mercado, en fin, las instituciones que constituyen el entramado de las relaciones interpersonales en el contexto de la lógica del Estado moderno, aunque son invisibles, se evidencian como visibles, como fetiches, y lo particular de ellas — las instituciones - es que se perciben como existentes (Hinkelammert, 1977, pp. 9-10). Aunque lo que se ve sean las edificaciones, en ellas acontecen las relaciones que se fetichizan. Por ello, una de las funciones propias de una educación religiosa, en perspectiva liberadora, es la crítica a la fetichización de las instituciones y la crítica a las idolatrías sacrales y seculares, que interpretan de manera distorsionada la realidad para lograr sus intereses manipuladores.

Karl Marx fue el que desarrolló la teoría de fetichismo para el análisis del fetichismo mercantil de las sociedades capitalistas (Hinkelammert, 1977, p. 13). En particular, Marx critica las relaciones mercantiles que giran en torno a la realidad del dinero o capital hasta pretender, incluso, antropomorfizarse, es decir, adquirir la apariencia de sujetos humanos; por ello, la mercancía adquiere un carácter misterioso que se proyecta ante los sujetos, pues el carácter social de su producción es asimilado como carácter natural de los productos, al margen de los productores (Marx, 1966, p. 38). Pero este nuevo sistema-mundo, centrado en la mercancía, se independiza del sujeto para vivir su propio juego.

El fetichismo de la mercancía revela un mundo caprichoso. Aparece toda la imagen del juego entre mercancías: Ellas luchan entre sí, hacen alianzas, bailan, se pelean, una gana, otra pierde. Todas las relaciones que se pueden formar entre hombres, se dan también entre mercancías (Marx, 1966, p. 13).

La transformación de los objetos en sujetos - en mercancías que establecen relaciones sociales entre sí- es resultado de las relaciones de producción de los sujetos, pero que han perdido su referencia, su vínculo vital con los sujetos que las han creado, para vivir una vida independiente (Marx, 1966, p. 38), a expensas de la lógica del mercado. Esta subjetividad de las cosas se reviste ahora de divinización, ya que proyectan en su misterio otro mundo, como politeísmo del mundo mercantil (Hinkelammert, 1977, p. 17) que, para Marx, se asemeja al mundo de la religión, el mundo de los dioses que representan a las mercancías:

Por eso, si queremos encontrar una analogía a este fenómeno, tenemos que remontarnos a las regiones nebulosas del mundo de la religión, donde los productos de la mente humana semejan seres dotados de vida propia, de existencia independiente, y relaciones entre sí y con los hombres. Así acontece en el mundo de las mercancías (Marx, 1966, p. 38).

Por su parte, la idolatrización es la tendencia dinámica de los sujetos a sacralizar realidades, cosas, animales, sujetos, entre otros, es decir, a rodearlos de un halo de misterio, desde el cual se relacionan como dioses o semidioses.

La idolatría surge de otros supuestos. Su punto de partida es la fe en la existencia de Dios, por un lado y, por otro, el desconocimiento (ingenuo o interesado) del Dios verdadero. El referente, en el primer caso, es el hombre ingenuo, primitivo, que confunde la magnitud de la realidad mundana con la magnitud de la realidad de Dios, o bien magnificando la primera o bien reduciendo la segunda; pero, como sea, es problema de imagen de Dios. 
En el segundo caso, el referente es el hombre bien situado, detentador del poder [...] que, astutamente, intenta manipular la realidad misma de Dios en favor de sus intereses. La idolatría, en este segundo caso, exige siempre víctimas humanas sacrificadas al dios en quien se cree, que será contrario, en su realidad y en sus planes, al Dios revelado por Jesús (Bravo, 1991, p. 38).

Así, realidades como la política, la economía, la tecnología, la racionalidad instrumental o el poderío militar, por estar revestidas de divinidad, pueden convertirse en ídolos que enajenan al sujeto y generan sistemas sacrificiales.

En la actualidad, hay que hablar de la divinización de las potencias, sobre la lógica de las relaciones de la idolatría con política; se "ha sustituido a Dios por otra realidad distinta, absolutizándola" (Sicre, Castillo \& Estrada, 1989, p. 56). Y las dos formas de idolatría del Estado se dan por medio del culto a la sabiduría política y el culto al poderío militar (Sicre, Castillo \& Estrada, 1989, pp. 58-59). Ante esta realidad, hasta la misma mentalidad moderna positivista del Estado se siente impotente por la entronización de poderes irracionales: "el 'espíritu nacional', la 'voluntad de poder', la nación, la raza, etc., como sustitutivos de un sujeto de la historia y portadores de su sentido" (Metz, 2002, p. 88). En la base de un Estado totalitario está la absolutización de la seguridad nacional.

Las ideologías de la seguridad nacional han contribuido a fortalecer, en muchas ocasiones, el carácter totalitario o autoritario de los regímenes de fuerza de donde se ha derivado el abuso del poder y la violación de los derechos humanos. En algunos casos pretenden amparar sus actitudes con una subjetiva profesión de fe cristiana (CELAM, 1979, nn. ${ }^{\circ} 314,547$, $549,1262)$.

Monseñor Óscar Arnulfo Romero, comentando el Documento de Puebla al respecto, señala que en virtud de la ideología de la seguridad nacional se enajena la voluntad de la persona humana poniéndola al servicio total del Estado, sometiendo al pueblo a la tutela de las élites políticas y militares, y obligando al ejército a cuidar la infraestructura económica y política particular so pretexto del interés general (Romero, 1979, p. 147).

Una de las expresiones es la absolutización de la organización política, al considerar como valor supremo la propia organización, subordinando toda realidad a la pretensión de la misma organización (Romero, 1979, p. 148). Estas formas de fetichización van acompañadas de actitudes idolátricas, como el afecto hacia estos dioses, generando el adulterio religioso y la confianza en estos ídolos como puntos de apoyo (Sicre, Castillo \& Estrada, 1989, p. 61).

La actitud más secularizada, en el ámbito de la política, termina siendo hondamente religiosa, ya que los ciudadanos quedan religados a la realidad política que, al no ser Dios, se convierte en una falsa religación.

Cuando se absolutiza un valor humano dándole, teórica o prácticamente, un carácter divino, se priva al hombre de su más alta vocación e inspiración y se empuja la cultura de un pueblo hacia una verdadera idolatría que lo mutila y lo oprime (Romero, 1979, p. 145).

Otro ámbito de religación idolátrica, señala José Luis Sicre, es la divinización de la riqueza, a partir de la relación extrínseca con la misma, ya sea porque convierte los bienes en fines de culto, divinizándolos como orientación fundamental de la vida, o porque las personas fomenten su 
propio culto por intereses económicos, el poder manifiesto del dinero (Sicre, Castillo \& Estrada, 1989, pp. 64-67).

La absolutización de la riqueza pone el ideal del hombre en "tener más" y por tanto disminuye el interés por "ser más" que debe ser el ideal del verdadero progreso del hombre y del pueblo. El deseo absoluto de "tener más" fomenta el egoísmo que destruye la convivencia fraternal de los hijos de Dios. Porque esta idolatría de la riqueza impide a la mayoría disfrutar de los bienes que el Creador hizo para todos y lleva a la minoría que lo posee todo a un gozo exagerado de esos bienes (Romero, 1979, p. 146).

Lo que hace complejo el asunto de la fetichización del mercado es el carácter religioso con el que se ha querido revestir la economía del mercado, la dimensión religiosa que se le atribuye a la economía neoliberal.

No se trata ya solamente de "legitimar" el sistema capitalista, con las escandalosas consecuencias que está teniendo [...] Se trata, sobre todo, de "sacralizar" semejante sistema, hasta convertirlo en "religión", la religión que va a salvar a la humanidad de estos tiempos (Castillo, 1997, p. 11).

Si uno de los pilares del sistema-mundo capitalista es la propiedad privada, esta también se puede absolutizar cuando se pierde el referente de la función social de la propiedad privada; si se absolutiza la propiedad privada, como afirma el Papa Juan Pablo II (1979, parte III, n. ${ }^{\circ} 4$ ), se grava a la humanidad con una hipoteca social, ya que no se logra la justicia de una distribución más justa y equitativa. Esta absolutización de la propiedad privada está en la base tanto de la violencia estructural y de la violencia represiva como del subdesarrollo económico, social y político (Romero, 1979, p. 146).

Al desenmascarar la supuesta universalidad y heroicidad del hombre, desenmascara también su inducida comprensión analógica a partir del hombre occidental, del hombre moderno de las sociedades de la abundancia. [...] Porque la mayoría de la humanidad está compuesta por pobres, y el hombre moderno es la excepción (Fernández, 1991, p. 54).

Por lo anterior, ante las realidades de la fetichización y la idolatrización, la educación religiosa escolar en perspectiva liberadora debe recuperar la fuerza crítica de la conciencia religiosa, para ayudar a los estudiantes en su tarea, como sujetos transformadores de su historia, de asumir una actitud desfetichizadora de las instituciones, es decir, debe deslegitimar las nuevas realidades absolutizadas (las empresas, la mercancía), y desenmascarar aquellas realidades que no son manifestación de la divinidad, como un signo de los tiempos o kairós, sino que se han fetichizado para enajenar la conciencia del sujeto, para hacer pasar por divino lo que es sencillamente una estrategia para dominar. Por tanto, la reflexión de la educación religiosa escolar debe formar para la sospecha de todo aquello que se pretende presentar como absoluto, desplazando la realidad del misterio, denunciando sus pretensiones de sentido unificador.

En un mundo dominado por la mercancía, es importante visibilizar lo invisible, es decir, desfetichizar las instituciones que surgen de la racionalidad del mercado, el dinero y la mercancía, razón por la cual la educación religiosa escolar debe asumir una postura crítica y suscitar en los estudiantes una actitud crítica ante el sistema-mundo del mercado. Las mercancías se absolutizan y su soberanía genera muerte o vida, y la conciencia social ha delegado en las instituciones la decisión sobre la vida o la muerte, como proyección de un dios de la propiedad privada (Hinkelammert, 1977, p. 22). 
Entonces, la propuesta de una educación religiosa escolar en perspectiva liberadora tiene, en la escuela, la función de enseñar a los estudiantes a criticar la racionalidad del sistema-mundo que se impone, con sus estrategias globalizantes de fetichización e idolatrización para aportar a la construcción de otro mundo posible en la lógica de la mundialización.

\section{La mediación de la teología de la liberación y la pedagogía liberadora en la educación religiosa escolar}

Al indagar por la fundamentación epistemológica de la educación, en el ámbito de la escuela, cabe indicar que en las instituciones educativas acontecen los saberes como mediaciones de las relaciones de enseñanza-aprendizaje. Uno de esos saberes es la educación religiosa escolar que, al igual que los otros, exige una comprensión de su estatuto epistemológico, es decir, la pregunta por su objeto de estudio y el método para abordarlo.

Ahora bien, si la razón de ser de la educación religiosa escolar es la formación en la comprensión y el ejercicio de la libertad religiosa, como dimensión del sujeto, ¿cuál es su fundamentación metódica? Por ello, aunque el área de educación religiosa tiene su objetivo de formación, no tiene su método propio de estudio, y debe acudir a la teología como fundamento primero y a la pedagogía como fundamento segundo.

Esta fundamentación epistemológica, desde la teología, y metódica, desde la pedagogía, no es neutral. La educación religiosa escolar, por un lado, está sujeta a las comprensiones de lo religioso desde las formas del quehacer teológico, dadas en algunas de las corrientes o escuelas teológicas, que le aportan a la comprensión de la educación religiosa escolar desde su propia reflexión hermenéutica; y por otro lado, la fundamentación metódica de la educación religiosa, desde la pedagogía, ha de contextualizarse desde las comprensiones propias de lo educativo, en los distintos enfoques pedagógicos. Por ello, la educación religiosa reclama la opción por cuál teología y cuál pedagogía son las más indicadas para su fundamentación.

La opción más favorable para una educación religiosa escolar en perspectiva liberadora es la mediación epistemológica de una teología de la liberación, que le permite al estudiante asumir lo religioso como un dinamismo de fe que implica la justicia, la praxis liberadora de las comunidades víctimas de las estructuras de pecado. De igual manera, la mediación de la pedagogía liberadora le permite recuperar la conciencia del protagonista de la propia educación: el sujeto, entendida esta como la toma de conciencia de su propio ser como gestor y constructor de su proyecto de vida, más allá de las prácticas pedagógicas clásicas que infantilizan y enajenan al sujeto.

La mediación de la teología de la liberación, como dinamismo de la fe y la justicia

Si la teología, como mediación cognitiva, existencial y práxica, es reflexión acerca del acontecer de Dios y/o su revelación en y a través de la historia, esta no es neutral sino que es intencionada, es decir, se realiza desde y donde se sistematiza esa experiencia de Dios, en contexto particular. Así, fundamentar la educación religiosa escolar desde una teología metafísica, ahistórica, abstracta y atemporal, es reducir el aporte de sentido que otorga la reflexión por el Absoluto desde un discurso original de sentido, a la experiencia de lo religioso en el sujeto. Si la educación religiosa escolar pretende aportar su sentido en el ámbito de la escuela, ella debe hacer su opción por una teología histórica, desde la realidad de los sujetos que pretenden vivir su experiencia de sentido en lo religioso.

Esta opción ha de asumirse desde la teología de la liberación, por cuanto esta teología es mucho más que un sistema de pensamiento con estructura interna, "[...] más bien se entiende con ella un modo de hacer teológico en el que se incluye también la práctica pastoral de la que surge y a la que acompaña" (Trigo, 2005, p. 5). Así, se podría afirmar que una educación religiosa escolar desde la perspectiva liberadora, entendida esta como praxis, es reflexión que reclama una práctica o una práctica que reclama su reflexión.

El centro y punto de partida de la reflexión de la experiencia espiritual de la teología de la liberación está en la experiencia, por parte de la comunidad, del Dios liberador, que con su revelación busca la realización de la humanidad; así, la fe, en esta perspectiva liberadora, constituye una fuerza que cambia al sujeto humano y lo impulsa a transformar las estructuras opresoras, ya sean de orden político, económico, social o espiritual.

No se contenta con una visión genérica y abstracta de la fe. A partir de lo general avanza hacia lo particular, es decir, desarrolla el sentido históricoliberador del evangelio. [...] Más aún, agrega a la temática teológica otros temas, los temas concretos de la opresión/liberación de los pobres, como por ejemplo: la producción económica, la gestión compartida del poder, la cuestión de la tierra, de la democracia, del proyecto histórico, etc. (Boff, 1993, p. 80).

El aporte fundamental de la teología de la liberación al área de educación religiosa está en la constitución de un sujeto que hace parte de una comunidad de base, que conjuntamente, iluminada por el Evangelio, desenmascara las realidades inhumanas y opresoras, 
las relaciones fetichizadas o idolátricas. Pero no es la constitución de cualquier sujeto, es la asunción y visibilización del sujeto desde el hombre y la mujer pobres, por cuanto la realidad del pobre, traducida en el contexto de la teología de la liberación, muestra que Dios no quiere que estos sigan siendo sometidos y mancillados por los poderes de distinto orden, en particular los políticos y económicos. Por ello, cuando Gustavo Gutiérrez se pregunta ¿dónde dormirán los pobres? (Gutiérrez \& Müller, 2005, pp. 111-172), encarna no solo todo el peso de la realidad de sufrimiento que padecen miles de hombres y mujeres, sino, además, la denuncia de las estructuras que han originado esa realidad.

Esta teología de la liberación no es solo diagnóstica y crítica de la realidad, también es propositiva, por cuanto actúa concretamente frente a la injusticia para generar situaciones de vida que restituyan, en justicia, la realidad de la dignidad humana. Así, en primer lugar busca potenciar la subjetualidad personal, es decir, incidir para que los hombres y mujeres, particularmente de los países empobrecidos, logren sus realizaciones y aspiraciones como personas con dignidad. Según Trigo:

[...] sujeto es el que vive, desde su libertad liberada, una libertad que no vive presa de sus pulsiones, de deseos o quereres automatizados y despóticos, sino que es capaz de obrar desde su corazón, desde la raíz de la que brota su querer, desde el núcleo en el que se origina su humanidad, desde esa matriz en la que se despliega su multiplicidad y a la vez se entrelaza y encauza (Trigo, 2005, p. 62).

Desde esta perspectiva, para la teología de la liberación la opción preferencial por el pobre se impone debido al profundo clamor de tantas e injustas formas de sufrimiento, de inhumanidad y de negación absoluta. Ellos son la razón de ser de la teología de la liberación y deben reflejarse tanto en su talente reflexivo como en el compromiso, que es la praxis del teólogo (Libanio, 2000). En la perspectiva del pobre, la teología de la liberación genera un sentido que expresa una dimensión de responsabilidad que compromete la acción reflexiva y práxica en beneficio de la relación histórica de los seres humanos, en su realización.

La óptica, que orienta el sentido de la teología de la liberación, les exige al teólogo y al creyente hablar de Dios desde los países empobrecidos, sin estar al margen de la realidad de sufrimiento y pobreza de miles de hombres y mujeres. Por ello, producir teología desde la especificidad de estas contingencias impone necesariamente la mediación de la pobreza y de la realidad de sufrimiento, por muy dolorosas que estas sean, pues esta realidad genera, nutre y transforma el discurso teológico, y si la teología la ignora, entonces no asume un discurso sobre Dios, mediado y encarnado como lo exige el evangelio (Gutiérrez \& Müller, 2005, pp. 51-77). En otras palabras, "no tendremos un lenguaje vivo sobre Dios sin una relación lúcida y fecunda con la cultura de una época y de un lugar" (Gutiérrez, 2003, p. 61).

Desde esta perspectiva liberadora, la educación religiosa escolar potencia y fundamenta su función crítica de la realidad, para denunciar las estructuras de opresión, estructuras de pecado, que son originadas por las prácticas explotadoras del poder económico, político y cultural de la sociedad. Además, exige, desde la praxis, un compromiso serio de transformación de estas estructuras de injustica para generar vida a los más empobrecidos; en otras palabras, la educación religiosa escolar en perspectiva liberadora forma desde el binomio fe-justicia.

Para lograr este objetivo de formar desde la relación de la fe con la justicia, el área de educación religiosa, por medio de la asignatura de educación religiosa escolar en perspectiva liberadora, debe potenciar la competencia y la actitud crítica de la reflexión de los estudiantes, que les permita denunciar las estructuras fetichizadas de opresión y proponer praxis alternativas de reconocimiento e inclusión de los sujetos víctimas del sistema. De igual manera, la praxis educativa de la educación religiosa escolar en perspectiva liberadora debe permitir la toma de conciencia de los docentes acerca de las relaciones de enseñanza-aprendizaje que acontecen en el aula, para que no se perpetúen dinámicas excluyentes ni ocultadoras de los estudiantes, generadoras de nuevas víctimas del sistema educativo.

La mediación de la pedagogía liberadora, como recuperación del sujeto

Uno de los principales aportes de la pedagogía liberadora, al igual que la teología de liberación, es la recuperación del sujeto como protagonista de su formación, a partir de la toma de conciencia de su propia realidad o contexto. Entonces, el aporte de la pedagogía y la teología liberadoras es el reconocimiento de los nuevos sujetos transformadores de la realidad, que producen pensamiento a partir de su praxis de liberación.

Quienes no eran considerados personas, quienes estaban fuera de la órbita de la dignidad, quienes se veían privados de derechos y solo tenían deberes, se tornan personas, sujetos en plenitud: las mujeres, los indígenas, los afrolatinoamericanos, los campesinos y las campesinas, los excluidos del modelo económico dominante, los niños y niñas de la calle, la tierra. Quienes fueron acusados de irracionales (conforme a las categorías de la razón instrumental, científicotécnica, dominadora de otros pueblos y depredadora 
de la naturaleza), se tornan poseedores de otra racionalidad más auténtica y radical: la simbólica, la utópica, la imaginativa, la convivial, la solidaria (Tamayo, 2003, pp. 1-15).

Si la acción educativa se centra en la conciencia de la condición del sujeto y del contexto en que se realiza la vida, como punto de partida para la realización del acto educativo, este proceso será el núcleo fundamental de la reflexión pedagógica. Por ello, esta tarea de concienciación está determinada por las relaciones dadas entre los sujetos en contextos articulados por la racionalidad de la época, para lo cual es necesario, entonces, determinar qué tipo de conciencia, con qué racionalidad y en qué contexto se construye la reflexión pedagógica. Ahora bien, si este contexto es el de opresión y su racionalidad es domesticadora, da lugar a la formulación y ejecución de la praxis educativa liberadora, como un proceso emancipatorio, realizado por los sujetos, gracias a la mediación alfabetizadora y problematizadora de la realidad, es decir, desde la propia vida, como autor y testigo de su historia (Freire, 1979/1970, p. 4, prólogo de Ernani María Fiori).

En consecuencia, se puede comprender el acto educativo como un ejercicio consciente o de concienciación, que se realiza en la historia y a través de la historia, lugar donde la liberación encuentra su sentido más profundo. A su vez, el acto educativo, como concreción de la pedagogía, ha de partir de la realidad y regresar a la misma, de forma transformada por la fuerza crítica de la liberación. Entonces, la educación se convierte en un acontecer transformador de la historia de los seres humanos, una práctica de la libertad, y no meramente una acción que se encarga de repetir los hechos, sin develar su significado y validez para la historia de una comunidad.

Así, la reflexión pedagógica liberadora propicia una praxis que le permite al sujeto reconocer y transformar la realidad en la cual vive, su propia realidad, para convertirla en un lugar de la vida y para la vida de hombres y mujeres que han sido excluidos del sistema; también una praxis desfetichizadora que desenmascara los ídolos, instrumentos de dominación que impiden la vida y generan la muerte. En este sentido adquieren significado las palabras de Paulo Freire (1974b, p. 45):

Naturalmente, en la línea profética, la educación se instauraría como un método de acción transformadora. Como praxis política al servicio de la permanente liberación de los seres humanos (...). Desde el punto de vista profético, no importa cuál sea el campo específico en que se imparta la educación, ella es siempre un esfuerzo de clarificación de lo concreto, para lo cual educadores-educandos, y educandos-educadores deben encontrarse ligados a través de su presencia actuante. Es siempre praxis desmitificadora que al desenmascarar la realidad de la conciencia, ayuda al desarrollo de la conciencia de la realidad.

Ahora bien, la reflexión pedagógica del acto educativo, desde la perspectiva liberadora, está llamada a asumir la historia como el lugar de la praxis educativa y de la liberación, en el cual el acto educativo es un proceso transformador, un dispositivo liberador, que ocurre dentro de la sociedad en la cual acontece; en primer lugar, si es autorreflexiva, liberadora de la educación, ha de denunciar sus propias estructuras dominadoras, como la educación bancaria, ya que no conduce a otro lugar que a la alienación del sujeto, a la (formación) producción en serie de sujetos unificados, de hombres y mujeres que deben actuar en el sistema como eslabones del mercado. Al respecto, Paulo Freire (2005, p. 114) afirma: "son exposiciones que 'domestican' o hacen que los educandos se 'duerman' arrullados". En segundo lugar, debe propender por la transformación de la realidad que permita que los sujetos sean protagonistas de la propia historia.

Para el caso de la formación en el área de la educación religiosa, si un determinado diseño de la asignatura educación religiosa escolar se fundamenta epistemológicamente en la teología de la liberación y metódicamente en la pedagogía liberadora, entonces se entiende la razón por la cual esta área estaría llamada a desarrollar un pensamiento que permee los momentos de aula, los procesos de enseñanza-aprendizaje, y transforme el quehacer educativo en praxis de liberación. La pedagogía, al igual que la teología, ha de ser profética, utópica y llena de esperanza; ciertamente, no será nada fácil, sobre todo en el contexto contemporáneo en el cual la educación está ofreciendo otras metas y haciendo exigencias que no pasan por el sujeto, sino por las necesidades del mercado.

La pedagogía liberadora se convierte prácticamente en una utopía que, bajo una mirada inmediatista, parecería ser desesperanzadora; pero, si recordamos que la utopía (u-topos, sin lugar; eu-topos, buen lugar) tiene al menos dos componentes: anhelo de lo no-existente y crítica de lo existente (Meza \& Arango, 2006, pp. 144-146), entonces, se cae en cuenta de que se trata de una meta que se logra con el paso del tiempo y el esfuerzo de todos los partícipes del acto educativo, y se hace liberadora para los sujetos y las sociedades que saben acogerla.

Este escenario, donde se gesta lo utópico, se puede lograr con procesos orientados por hombres y mujeres que quieran jugarse la vida por una educación que sea liberadora y no simple repetidora del sistema que impone una determinada forma de ser $y$ 
pensar. Para Freire (2007, pp. 27-29), el sujeto tiene la posibilidad de salir de la opresión en la cual se encuentra y la educación es el camino para que esta posibilidad se concrete; pero no basta la voluntad de una sola persona, sino que son necesarios el reconocimiento y la cooperación de los otros:

Una pedagogía utópica de denuncia y de anuncio como la nuestra, tiene que ser un acto de conocimiento de la realidad denunciada a nivel de la alfabetización y post-alfabetización que constituyen, en cada caso, una acción cultural. Por esto se pone el acento sobre la problematización continua de las situaciones existenciales de los educandos tal cual ellas son presentadas en las imágenes codificadas. Mientras más progrese la problematización, más penetran los sujetos en la esencia del objeto problematizado, y más capaces son de des-velar esta esencia. En la medida en que la des-velan, se profundiza su conciencia naciente, conduciendo así a la concientización de la situación por las clases pobres (Freire, 1974a, p. 95).

La pedagogía liberadora ha de permitir que el sujeto se forme íntegra e integralmente, es decir, que desarrolle todas sus dimensiones y que junto con los demás, se creen las condiciones para que la sociedad, de la cual se forma parte, se convierta en un lugar en donde se pueda vivir mejor y con dignidad. El mismo Freire (2007, p. 84) lo dice:

Una educación que posibilite al hombre para la discusión valiente de su problemática, de su inserción en esa problemática, que lo advierta de los peligros de su tiempo para que, consciente de ellos, gane la fuerza y el valor para luchar, en lugar de ser arrastrado a la pérdida de su propio 'yo', sometido a las prescripciones ajenas.

De este modo, la pedagogía liberadora crea una opción para el sujeto (Mesa, 1986, p. 24), tanto en sentido individual como social, pensando en particular en los hombres y mujeres que más necesitan un proceso de liberación, porque históricamente han sido víctimas de la injusticia y han sido enajenados. Esta opción liberadora no es excluyente, incluye al oprimido y al opresor, porque, de no hacerlo, repetiría el error que ha venido cometiendo la educación elitista, de clase, de exclusión de unos por su condición de pobreza.

Por tanto, la pedagogía liberadora está dirigida a todas las personas, pues así como los pobres deben liberarse, también han de hacerlo aquellos que la han utilizado para "atarse" al poder. De no ser así, ni unos ni otros participarían en la construcción una nueva sociedad. La situación pide que ambos, oprimido y opresor, víctima y victimario, se liberen, pues una mirada aguda a cada uno permite identificar las cadenas que no los dejan dar el paso para ver al otro como su hermano.

En el contexto de la globalización, la opción por los pobres desde la educación significa optar por ellos como sujetos históricos, capaces de participar activamente en la búsqueda y en la construcción de una civilización alternativa, capaces de plantearse una nueva organización del mundo que rompa con las estructuras excluyentes y crea en la utopía de una nueva era de los pueblos, apostando confiadamente en sus posibilidades y potencialidades (Mesa, 1986, p. 119).

Por lo anterior, se hace realidad el propósito de la pedagogía liberadora enunciado por Mario L. Peresson, de transformar las instituciones, las empresas y los proyectos desde una educación para la solidaridad, una 
educación en perspectiva liberadora que libere a los sujetos y sus estructuras, en sujetos liberados y en estructuras liberadoras:

Tenemos una tarea pedagógica inmensa en un contexto donde desaparece el horizonte del bien común y donde cada uno busca su propio provecho en el mercado, y la exclusión social se profundiza. De ahí que se plantea como una misión impostergable el emprender un esfuerzo educativo formal e informal para transformar las instituciones, empresas y proyectos excluyentes y políticas de exclusión (Peresson, 1998, p. 121).

Sin embargo, la fundamentación de la educación religiosa escolar desde la pedagogía liberadora no excluye la mediación de otras ciencias. Como área de formación, la educación religiosa debe tener la claridad organizativa en lo referente al proceso de aprendizaje y producción de conocimiento, consciente de que la inteligencia de la fe no solo recrea constantemente otros ámbitos del saber humano, también ella puede ser comprendida desde los otros saberes: psicopedagógico, antropológico, sociopolítico, histórico, entre otros.

Así, las mediaciones de estas ciencias sociales le aportan a la educación religiosa escolar el "estructurarse como cuerpo de conocimientos, valores, habilidades y destrezas, estrategias cognoscitivas y actitudinales que facilitan la construcción y apropiación del conocimiento, que ayudan a los estudiantes a interpretar, conceptuar, analizar, expresar y valorar la experiencia religiosa" (Conferencia Episcopal de Colombia, 2000, p. 26). Y desde esa lógica, la educación religiosa escolar pueda aportar a la relación de enseñanza-aprendizaje su capacidad hermenéutica, liberadora, utópica y de fe.

Estas mediaciones contextuales de las ciencias sociales colaboran para que el área de educación religiosa aporte su saber, iluminado por la fe, con el objeto de ahondar en la estructura ontológica del ser humano, que a la vez transforma la realidad sociohistórica que lo rodea. Como estas mediaciones de los saberes buscan la formación integral del sujeto en el contexto social, se pretende formar en las distintas dimensiones que constituyen lo humano, más allá de una confesionalidad.

De igual manera, la educación religiosa escolar ha de abrirse a los aprendizajes provenientes de otros credos o cosmovisiones religiosas y seculares, en un diálogo interreligioso, que supere los exclusivismos confesionales y cosmovisionales, que enfatizan un solo sentido de la verdad, buscando formar ciudadanos, hombres y mujeres, para la convivencia social, que puedan reconocer las dimensiones y manifestaciones plurales de la experiencia religiosa, y determinando los valores que esta genera y articula con los problemas que entretejen la vida humana.

Así, el área de educación religiosa debe contribuir y fomentar en las comunidades académicas las competencias necesarias para poder usar el saber religioso en contextos vitales. De no ser así, el saber religioso será identificado como algo inútil y desligado de la vida, con lo que se exacerbarían aquellos discursos que escinden lo trascendente de lo contingente, lo humano de lo divino, lo sagrado de lo profano, la fe de la razón, el comprender del explicar, entre otros. Una fe que no es capaz de dar sentido a las contingencias en que deviene la vida de los hombres y mujeres es la que propicia discursos desencarnados, transmisión de verdades de un Dios omnipotente y alejado de la historia humana.

Además, la educación religiosa escolar no puede ser un saber aislado de los demás saberes que se dan en la escuela; el proceso de enseñanza aprendizaje, para que sea integral, debe correlacionarse a partir de 
procesos. Por ello, el proceso de formación de la dimensión trascendente del sujeto exige el aporte de los otros saberes, para enriquecer la comprensión del mundo de la vida y para aportar desde sus métodos, la comprensión de lo religioso y de la religión.

[...] no se sitúa, sin embargo, junto a ellas — las otras disciplinas - como algo accesorio, sino en un necesario diálogo inter-disciplinar. Este diálogo ha de establecerse ante todo, en aquel nivel en que cada disciplina configura la personalidad del alumno. Así la presentación del mensaje cristiano en el modo de concebir desde el Evangelio, el origen del mundo y el sentido de la historia, el fundamento de los valores éticos, la función de las religiones en la cultura, el destino del hombre, la relación con la naturaleza. [...] La enseñanza religiosa escolar, mediante este diálogo inter-disciplinar, funda, potencia, desarrolla y completa la acción educadora de la escuela (Conferencia Episcopal de Colombia, 2000, p. 29).

Por lo anterior, si la pretensión última de la escuela es la formación del sujeto integral, para que pueda vivir conscientemente como protagonista de la historia y transformador de la misma, solo puede cumplir su cometido estableciendo un diálogo interdisciplinar en favor de la concienciación del sujeto. La educación religiosa escolar no es el único saber responsable de la concienciación del sujeto, los demás saberes deben aportar, desde sus epistemologías, a la comprensión de la realidad que le permita al sujeto aproximarse a ella para transformarla.

\section{Sobre los autores}

David Eduardo Lara-Corredor es profesor asistente de la Facultad de Teología de la Pontificia Universidad Javeriana. Magíster en teología de la Pontificia Universidad Javeriana, especialista en derechos humanos de la Escuela Superior de Administración Pública. Licenciado en filosofía de la Universidad Santo Tomás.

Juan Alberto Casas-Ramírez es candidato al doctorado en teología, magíster en teología y licenciado en ciencias religiosas de la Pontificia Universidad Javeriana (Bogotá, Colombia). Profesor de tiempo completo del área de teología bíblica en la Facultad de Teología de esa Universidad. Miembro del grupo de investigación Didaskalia, reconocido por Colciencias.

Daniel de Jesús Garavito-Villarreal es licenciado en Educación, especialidad en Ciencias Sociales: Universidad Libre de Colombia. Estudios filosofía y teología: Seminario Regional Juan XXIII (Barranquilla-Colombia). Magister en filosofía: Pontificia Universidad Javeriana. Magister en Teología: Pontificia Universidad Javeriana. Doctor en Teología: Pontificia Universidad Javeriana. Actualmente es profesor investigador de tiempo completo de la Faculta de Teología de la Pontificia Universidad Javeriana. Coordinador del área de Teología de la Acción Humana. Miembro del grupo de Investigación Didaskalia, con registro de CVLAC y GrupLAC ante Colciencias.

José Luis Meza-Rueda es doctor y magíster en teología de la Pontificia Universidad Javeriana, magíster en docencia de la Universidad de La Salle, licenciado en estudios religiosos de la Universidad de La Salle. Profesor asociado de la Universidad Javeriana. Miembro del grupo Didaskalia.

José Orlando Reyes-Fonseca es Doctor, Magister, Licenciado y Profesional en Teología, Pontificia Universidad Javeriana; Magister en Educación, Pontificia Universidad Javeriana; Especialista en Docencia Universitaria, Universidad El Bosque. formador e investigador en asuntos académicos pertinentes a las relaciones entre educación y teología en procesos de liberación integral de la persona humana. 
Gabriel Alfonso Suárez-Medina es licenciado en educación, filosofía y letras de la Universidad Santo Tomás. Teólogo de la Pontificia Universidad Salesiana. Licenciado en teología de la Pontificia Universidad Javeriana. Doctor en filosofía de la Pontificia Universidad Gregoriana, Roma. Actualmente, docente e investigador de la Pontificia Universidad Javeriana.

\section{Referencias}

Aguirre, M. (1991). J. A. Comenio en los albores de la escuela moderna. Revista Educación y Pedagogía, 2 (6), 75-84.

Boff, C. (1993). Epistemología y método de la teología de la liberación. En Ignacio Ellacuría \& Jon Sobrino (eds.). Mysterium liberationis. Conceptos fundamentales de la teología de la liberación, Tomo II, 79113. San Salvador: San Salvador: Universidad Centroamericana José Simeón Cañas, UCA Editores.

Bravo, C. (1991). Tres ateísmos, dos idolatrías y un solo Dios verdadero. Christus, Vol. 649, pp. 37-41.

Calvez, J-I. (2005/2003). Globalización, mundialización. Aspectos económicos, políticos, culturales y religiosos. Orientaciones Universitarias, Globalización, mundialización y verdad como valores, 37, 38-57. Disponible en: http://www.javeriana.edu.co/puj/rectoria/publicaciones/ Documentos/Calvez-Globaliz-3.pdf

Carrera-i-Carrera, J. (2005). Mundo global, ética global. Orientaciones Universitarias, globalización, mundialización y verdad como valores, 37, 7-37. Disponible en: http://www.javeriana.edu.co/puj/rectoria/ publicaciones/Documentos/Carrera-Mundo\%20global.pdf

Castillo, J. M. (1997). Los pobres y la teología. ¿Qué queda de la teología de la liberación? Bilbao: Descleé de Brouwer.

Cavadi, A. (1998). Ser profetas hoy. La dimensión profética de la experiencia cristiana. Santander: Sal Terrae.

Colombia (1991). Constitución Política de Colombia. Bogotá: Impreandes. Disponible en: http://www.alcaldiabogota.gov.co/sisjur/normas/ Norma1.jsp?i=4125

Colombia (1994). Ley 115 de 1994, por la cual se expide la Ley General de Educación. Diario Oficial, 41.214, 8 de febrero de 1994. Disponible en: http://www.alcaldiabogota.gov.co/sisjur/normas/Norma1.jsp?i=292

Conferencia Episcopal de Colombia, CEC (2000). Escuela y religión. Hacia la construcción de un modelo de educación religiosa. Bogotá: Secretariado Permanente para el Episcopado Colombiano, SPEC.

Conferencia Episcopal Latinoamericana y del Caribe, CELAM (1979). Documento de Puebla. Bogotá: Paulinas. Disponible en: http://www. celam.org/doc_conferencias/Documento_Conclusivo_Puebla.pdf

Conferencia Episcopal Latinoamericana y del Caribe, CELAM (1992). Documento de Santo Domingo. Instrumentum laboris. Bogotá: Ediciones Paulinas. Disponible en: http://www.celam.org/doc_conferencias/ Documento_Conclusivo_Santo_Domingo.pdf

Fernández, D. (1991). La posmodernidad como desafío (aportes para un manifiesto). Christus, 56 (644), 51-55.

Ferrer, J. J. (2000). 'Quod omnes tangit, ab omnibus tractari debet': una 'questio disputata' de epistemología moral en la teología católica. En Javier Gafo (ed.), Pedro Tarquis-Alfonso, Riay Tatary-Bakry, Francesc Torralba-Roselló, Baruj A. Garzón-Serfaty, Jorge José Ferrer \& Diego Gracia. Bioética y religiones: el final de la vida, 127-152. Madrid: Universidad Pontificia Comillas, Instituto Católico de Artes e Industrias \& Instituto Católico de Administración y Dirección de Empresas, ICAI-ICADE. 
Freire, P (1974a). Concientización. Teoría y práctica de la liberación. Bogotá: Asociación de Publicaciones Educativas.

Freire, P. (1974b). Las iglesias, la educación y el proceso de liberación humana en la historia. Buenos Aires: La Aurora.

Freire, P. (1979/1970). Pedagogía del oprimido. México, D.F.: Siglo XXI.

Freire, P. (2005). Pedagogía de la esperanza. México, D.F.: Siglo XXI.

Freire, P. (2007). La educación como práctica de la libertad. México, D.F.: Siglo XXI.

Gafo, J. (2003). Bioética teológica. Madrid: Universidad Pontificia Comillas, Instituto Católico de Artes e Industrias \& Instituto Católico de Administración y Dirección de Empresas, ICAI-ICADE.

González, J. I. (1997). Derechos humanos, deberes míos. Pensamiento débil, caridad fuerte. Bilbao: Sal Terrae.

Gutiérrez, G. \& Müller, G. L. (2005). Del lado de los pobres. Teología de la liberación. Lima: Centro de Estudios y Publicaciones, CEP.

Gutiérrez, G. (2003). La densidad del presente. Salamanca: Sígueme.

Hinkelammert, F. (1977). Las armas ideológicas de la muerte. El discernimiento de los fetiches: capitalismo y cristianismo. Costa Rica: Educa.

Juan Pablo II (1979). Discurso inaugural de la III Conferencia Episcopal Latinoamericana y del Caribe, CELAM. En Conferencia Episcopal Latinoamericana y del Caribe, CELAM, Documento de Puebla. Bogotá: Paulinas. Disponible en: http://www.celam.org/doc_conferencias/Documento Conclusivo_Puebla.pdf, http://www.vatican.va/holy_father/john_paul_ii/ speeches/1979/january/documents/hf_jp-ii_spe_19790128_messicopuebla-episc-latam_sp.html

König, F. (1989). El hombre y la religión. En José Luis Sicre, José María Castillo \& Juan Antonio Estrada. La Iglesia y los profetas. Córdoba: El Almendro.

Libanio, J. B. (2000). Gustavo Gutiérrez. Madrid: Ediciones San Pablo.

Marx, K. (1966). El capital. México: Fondo de Cultura Económica, FCE.

Mesa, J. A. (1986). Educación personalizada liberadora. Bogotá: Indo-American Press Service.

Metz, J. B. (2002). Dios y tiempo. Nueva teología política. Madrid: Trotta.

Meza, J. L. \& Arango, Ó. (2006). Discernimiento y proyecto de vida, dinamismos para la búsqueda de sentido. Bogotá: Facultad de Teología, Pontificia Universidad Javeriana.

Peresson, M. (1998). Misión profética de la educación católica en los umbrales del tercer milenio. Bogotá: Indo-American Press Service.

Ricoeur, P. (2008). Fe y filosofía. Problemas del lenguaje religioso. Buenos Aires: Prometeo Libros \& Pontificia Universidad Católica Argentina.

Romero, Ó. A. (1979). Misión de la Iglesia en medio de la crisis del país. San Salvador: Universidad Centroamericana José Simeón Cañas, UCA Editores. Disponible en: http://servicioskoinonia.org/romero/ homilias/B/790806.htm

Sicre, J. L.; Castillo, J. M. \& Estrada, J. A. (1989). La Iglesia y los profetas. Córdoba: El Almendro.

Tamayo, J. J. (2003). Las teologías de Abya-Yala, valoración desde la teología sistemática. Pasos, 109, 1-15.

Tatary-Bakry, R. (2000). Islam, bioética y final de la vida. En Javier Gafo (ed.), Pedro Tarquis-Alfonso, Riay Tatary-Bakry, Francesc TorralbaRoselló, Baruj A. Garzón-Serfaty, Jorge José Ferrer \& Diego Gracia. Bioética y religiones: el final de la vida, 65-86. Madrid: Universidad Pontificia Comillas, Instituto Católico de Artes e Industrias \& Instituto Católico de Administración y Dirección de Empresas, ICAI-ICADE.

Trigo, P. (2005). ¿Ha muerto la teología de la liberación? Bogotá: Facultad de Teología, Pontificia Universidad Javeriana. 